\title{
Study of the Determinants of Dietary Diversity among Pregnant Women in the Dakar Region (Senegal) in 2017
}

\author{
Theresa Stella Esperance Fouckou Moko ${ }^{1 *}$, Jean Augustin Diegane Tine², \\ Maty Diagne Camara ${ }^{3}$, Adama Faye ${ }^{2}$
}

\author{
${ }^{1}$ Institute of Health and Development, Public Health Department, Faculty of Medicine, Pharmacy and Odontology, Cheikh Anta \\ Diop University, Dakar, Senegal \\ ${ }^{2}$ Department of Preventive Medicine and Public Health, Faculty of Medicine, Pharmacy and Odontology, Cheikh Anta Diop \\ University, Dakar, Senegal \\ ${ }^{3}$ Food and Nutrition Division of the Ministry of Health and Social Action, Dakar, Senegal \\ Email: *theresamoko@gmail.com
}

How to cite this paper: Moko, T.S.E.F., Tine, J.A.D., Camara, M.D. and Faye, A. (2021) Study of the Determinants of Dietary Diversity among Pregnant Women in the Dakar Region (Senegal) in 2017. Food and Nutrition Sciences, 12, 578-590. https://doi.org/10.4236/fns.2021.126043

Received: May 11, 2021

Accepted: June 22, 2021

Published: June 25, 2021

Copyright $\odot 2021$ by author(s) and Scientific Research Publishing Inc. This work is licensed under the Creative Commons Attribution International License (CC BY 4.0).

http://creativecommons.org/licenses/by/4.0/

\begin{abstract}
Introduction: Many health problems in pregnant women result in part from inadequate nutrition. Much progress has been made in improving the nutritional situation in Dakar, but it remains a concern to this day. Promoting dietary diversity is an effective way to combat any kind of nutrient deficiency. This study aims to investigate the determinants of dietary diversity in pregnant women in the Dakar region. Method: It was a cross-sectional, descriptive, analytical study with a three-stage survey. The calculated sample was 292 pregnant women. Socio-demographic, economic, pregnancy-related data, related to practices and knowledge on nutrition were collected using a questionnaire and an observation grid. The collection was conducted from November 01 to December 15, 2017 among pregnant women in the Dakar region. Data were entered using epi info software and analyses were done with R. Simple linear regression was used to find the explanatory factors of dietary diversification. The fit of the regression model was done by the Hosmer Lemeshow test. The odds ratios were measured with a $5 \%$ alpha risk. Results: A total of 300 pregnant women were surveyed in two different health districts. The mean dietary diversification score was 5.47, the median was 5 and the standard deviation was 1.24 . Factors associated with dietary diversity were age $-1.14[-1.8 ;-0.48]$, place of follow-up 0.39 [0.12; 0.67], number of children $0.56[0.25 ; 1.1]$, mineral water consumption 0.27 [0.001; 0.5$]$ and husband's income 0.79 [0.24; 1.35]. Discussion-Conclusion: The Dietary Diversity Score was average, although it is important to note a real lack of dietary
\end{abstract}


variety among women, which needs to be corrected through quality communication at prenatal consultations, but also the training of midwives in the field of nutrition remains essential.

\section{Keywords}

Determinants, Dietary Diversity, Pregnant Women, Dakar

\section{Introduction}

Dietary diversity is an essential concept in the fight against malnutrition, by excess or by default, in all age groups, especially in developing countries. It is the secret of a healthy and balanced diet, especially for pregnant women, which is very crucial and determining the survival and good health of the fetus and the mother. It determines the number of different food groups consumed by an individual or household over a period. In many developing countries, common maternal undernutrition results in poor fetal development and an increased risk of pregnancy complications. Maternal and child undernutrition is responsible for more than $10 \%$ of the global burden of disease [1]. In many developing countries, common maternal undernutrition leads to poor fetal development and an increased risk of pregnancy complications.

In Senegal, according to the Multiple Indicator Cluster Survey [2], stunting, one of the three forms of malnutrition, is estimated at $27 \%$. However, it originates during the opportunity window that extends from conception to the age of two (the first 1000 days [3]). Women who are stunted are likely to give birth to children of low birth weight and size. This is the inter-generational cycle of malnutrition and explains the cycle of poverty, low micronutrient intake and malnutrition [4]. This situational analysis shows that the remedy to nutritional problems among pregnant women in ANC is not only iron or micronutrient supplementation, but above all nutritional revolution, a radical change in dietary behavior. Dietary diversity meets the nutritional needs not only of the woman but also of the fetus. A good intra-uterine nutrition is essential for the good emotional, physical, mental, and cognitive growth of the child. This study updates the nutritional data of pregnant women in the Dakar region and provides information on the determinants of dietary diversity among pregnant women in order to intervene to improve the health of the mother and child.

\section{Methodology}

\section{Setting of the study}

The study was conducted in the Dakar region, the political, economic, and cultural capital of Senegal. It is in the extreme west of the Cape Verde peninsula, on the Atlantic Ocean and covers an area of $550 \mathrm{~km}^{2}$, or $0.28 \%$ of the national territory. It is limited to the east by the region of Thies and by the Atlantic 
Ocean in its northern, western, and southern parts. It is subdivided into (04) departments, (10) arrondissements, (43) arrondissement communes, (02) rural communities, (04) towns and (03) communes. Because of the rare rainfall, its climate is said to be "desert".

We chose two health districts, one in the urban area (Gaspard Camara), the other in the peri-urban area (Khadim Rassoul), for the following reasons: we wanted to compare the nutritional situation in the two areas (urban and peri-urban), to learn about women's dietary habits and the associated factors, and to update the data on dietary diversity in the Dakar region.

\section{Type and period of the study}

This was a cross-sectional, descriptive, analytical study with a three-stage survey. Data were collected from November 01 to December 15, 2017.

\section{Study population}

All pregnant women ranging from the first week of pregnancy to the day before delivery present at prenatal consultation in the two health centers.

\section{Sampling}

The sample size was calculated with the Schwartz formula:

$$
n_{0}=\varepsilon^{2} \cdot \frac{P(1-P)}{i_{2}}
$$

$n=$ number of pregnant women needed to conduct the study.

For a risk $\alpha=5 \%, \varepsilon=$ reduced variance 1.96 .

$p=$ proportion of women with a low dietary diversity score (reference: PINKK survey in Kolda and Kedougou in 2015 by ISED $\mathrm{p}=0.73$ ) [5].

$q=$ complement of $p=(1-p)$.

$i=$ desired precision $=5 \%$.

The sample calculated was 292 pregnant women. We rounded up to 300 and the final size was 300 pregnant women surveyed in our study.

The sampling procedure: consecutive recruitment of eligible patients until the required sample size was reached for each study site.

\section{Data collection tool}

A questionnaire divided into five parts:

- Socio-demographic characteristics (age, marital status, ethnicity, housing with mother or mother-in-law, housing with husband, number of children, number of people in the household).

- Occupational and economic characteristics (education, level of education, occupation, employment, type of employment, income-generating activity, wife's estimated income, husband's occupation, husband's employment, husband's estimated income, possession of a social security grant).

- Pregnancy characteristics (age of pregnancy, iron intake, number of prenatal consultations performed, place of pregnancy follow-up).

- Food knowledge and practices (knowledge of good nutrition practices, different cooking methods used by women, activities related to food production, hygiene practices used). 
- Measurement of dietary diversity (any food and drink consumed from morning to evening during the 24 hours preceding the survey).

\section{Collection method}

The questionnaire was administrated to the pregnant women at the side of the prenatal consultation room after the consultation. An information and consent document were presented to them to obtain their free and clear consent before administering the questionnaire.

\section{Operational definition of variables}

\section{Dietary diversity}

It was appreciated through the number of food groups that women had consumed in the seven days before the interview. For the food groups to be taken into account we had chosen eleven, a choice related to the survey on dietary diversity in households conducted in the regions of Kedougou and Kolda in 2015 (5) These include: 1) Cereals, Roots and tubers 2) Legumes 3) Nuts and seeds 4) Dairy products 5) Meat products 6) Gibblets 7) Eggs 8) Dark green leafy vegetables 9) Fruits and vegetables rich in vitamin A 10) Other fruits 11) Other vegetables.

\begin{tabular}{|c|c|}
\hline \multicolumn{2}{|l|}{ socio-demographic characteristics } \\
\hline Age & ANC booklets \\
\hline \multirow[t]{5}{*}{ Marital status } & Monogamous married \\
\hline & Polygamous married \\
\hline & Divorced \\
\hline & Widowed \\
\hline & Single \\
\hline \multirow[t]{6}{*}{ Ethnicity } & Wolof \\
\hline & Serer \\
\hline & Diola \\
\hline & Pulaar \\
\hline & Mandingo \\
\hline & foreign ethnicities \\
\hline Housing with mother-in-law or mother & yes/no \\
\hline Housing with husband & yes/no \\
\hline Number of children & Should be said \\
\hline Number of people in the household & Should be said \\
\hline \multicolumn{2}{|c|}{ Professional and economic characteristics } \\
\hline Education or literacy & yes/no \\
\hline \multirow[t]{3}{*}{ Level of education } & Primary \\
\hline & Secondary \\
\hline & University \\
\hline Occupation & Should be said \\
\hline Wage employment & yes/no \\
\hline Type of employment & Should be said \\
\hline
\end{tabular}




\section{Continued}

\begin{tabular}{ll}
\hline Income-generating activity & $\begin{array}{l}\text { handicraft work } \\
\text { cash crop } \\
\text { small } \\
\text { business/salesperson } \\
\text { domestic worker } \\
\text { other to be specified }\end{array}$ \\
\hline Income & yes/no \\
\hline Estimated income & $\begin{array}{l}\text { less than or equal to } 50.000 \\
\text { more than } 50.000\end{array}$ \\
\hline Husband's occupation & \begin{tabular}{l} 
Should be said \\
\hline Husband's job
\end{tabular} \\
\hline Income of the head of the household & yes/no be said \\
\hline Estimated income of the head of the household & $\begin{array}{l}\text { less than or equal to } 50.000 \\
\text { more than } 50.000\end{array}$ \\
\hline
\end{tabular}

Pregnancy characteristics

\begin{tabular}{ll}
\hline Age of pregnancy & health booklets \\
\hline Folic iron intake & yes/no \\
\hline Number of prenatal consultations & health booklets \\
\hline Place of follow-up & $\begin{array}{l}\text { Gaspard Camara health center } \\
\text { Khadim Rassoul health center }\end{array}$ \\
\hline Nutritional knowledge and practices & $\begin{array}{l}\text { Diversification of food consumed, } \\
\text { Respect of food hygiene requirements, } \\
\text { Adequate food preservation }\end{array}$ \\
\hline The cooking methods & $\begin{array}{l}\text { broth } \\
\text { steaming } \\
\text { cooking in oil }\end{array}$ \\
\hline
\end{tabular}

The activities oriented in the production of yes/no

food

Hygiene practices used

Consumption of tap water

Consumption of mineral water,

Consumption of water from wells, rains, and rivers,

Washing of hands before meals,

Washing of hands after leaving the toilet

Washing of food before consumption

\section{Measuring dietary diversity}

Everything the pregnant woman had consumed per day during the seven days preceding the survey inside or outside the household

before the survey.
Breakfast

Snack

Lunch

Snack

Dinner 


\section{Statistical analysis}

The analysis was done with the software Epi info 7 version 2.2.6 and $\mathrm{R}$ version 3.4.4 and included a descriptive part and an analytical part.

The descriptive part consisted of expressing the qualitative variables by the frequency and the $95 \%$ confidence interval, and the quantitative variables by the mean and its standard deviation.

The analytical part included the bivariate analysis and the multivariate analysis.

In the bivariate analysis, Student's $t$ test and ANOVA were used to make comparisons of means. For cases where the distribution was not normal, the non-parametric Wilcoxon (Mann-Whitney) test was used. This analysis allowed us to sort the variables with a p-value of less than 0.20 for modeling. During the multivariate analysis, all variables with a p-value less than 0.20 were included in the multiple linear regression analysis to investigate the relationships of factors associated with dietary diversity. The top-down stepwise nested model method had been used to select the final model by removing at each level the variable with the largest $p$-value in the model. The anova function was used for comparison between two nested models after removing one variable. The significance level of the test was set at $5 \%$. The predictive quality of the chosen model was studied through the coefficient of determination $\mathrm{R}^{2}$ and the Akaike Information Criterion (AIC). The validity of the model was verified by analysis of the residuals.

Free and informed consent was sought from the participants by reading the information sheet and signing the consent form. Participation in the survey was voluntary and without coercion. The confidentiality of the survey was ensured. The identity of the women surveyed was anonymously protected.

\section{Results}

A total of 300 pregnant women were surveyed, 50\% in the Gaspard CAMARA health center and 50\% in the Khadim Khassoul health center.

\section{Socio demographic characteristics}

Women age was between 16 and 45 years. The average age of women surveyed was 28.02 years with a standard deviation of 5.4 years and a median of 28 years. The age of the women was classified into two groups: women between 16 and 19 years (5.3\%) and between 19 and 45 years (94.7\%). More than half (56\%) lived with their mother or mother-in-law, compared to $44 \%$. As for the number of children per woman, $93 \%$ had between 0 and 03 children and $7 \%$ had between 04 and 07 children. As for the number of persons living in the household, the average was 5.16 with a standard deviation of 1.77 and a median of 5 . The number of persons living in the household was between 0 and 11 and was divided into two modalities: the number of persons between 0 and $10(99.7 \%)$ and the number of persons living in the household greater than $10(0.3 \%)$.

\section{Professional and economic characteristics}

$82.67 \%$ were educated and $17.33 \%$ were not. Primary (30.65\%), secondary (40.32\%), and higher (29.03\%). More than half had an income $52.33 \%$, com- 
pared to $47.67 \%$. Among those who had an income $(n=157), 59.87 \%$ of the women estimated their income to be less than or equal to 50,000 $\mathrm{fcfa}$, and $40.13 \%$ had an income greater than $50.000 \mathrm{fcfa}$.

As for the social security grant $(n=300)$, most of the women $(90.33 \%)$ did not benefit from it, while only $9.67 \%$ did. $81.95 \%$ of the women estimated their husbands' income to be greater than 50.000 FCFA and $18.05 \%$ of the women estimated it to be less than or equal to 50.000 FCFA.

\section{Pregnancy-related characteristics}

The age of pregnancy was divided into three modalities ( $\mathrm{n}=300), 16.67 \%$ were in the first trimester of pregnancy, $46 \%$ were in the second and $37.33 \%$ in the third. Concerning the intake of folic iron at the time of pregnancy $95.67 \%$ of the women had declared to have already taken folic iron at least once during their pregnancy, against $4.33 \%$.

\section{Knowledge of nutritional practices}

Regarding knowledge on good nutrition practices, $(n=300)$, almost all the women answered yes to the respect of hygiene rules $99.63 \%$, against $0.67 \%$. $78.60 \%$ kept their food properly. Concerning the main cooking methods used ( $\mathrm{n}$ $=300), 98.33 \%$ declared that they cooked their food with heating oil, $6.67 \%$ steamed their food. Finally, 98.33\% declared to make broths.

Regarding the exercise of activities oriented in the production of foodstuffs, $97 \%$ did not exercise any activity related to the production of foodstuffs, against only $3 \%$ (Table 1 ).

Table 1. Characteristics of women $(\mathrm{N}=300)$.

\begin{tabular}{lcc}
\hline \multicolumn{1}{c}{ Characteristics of women } & $\begin{array}{c}\text { Frequencies } \\
\text { absolute (n) }\end{array}$ & $\begin{array}{c}\text { Relative frequencies } \\
\text { (r) }\end{array}$ \\
\hline Marital status & & \\
Monogamous brides & 235 & 78.33 \\
Polygamous Married & 51 & 17 \\
Divorced & 1 & 0.33 \\
Single & 12 & 4 \\
Widowed & 1 & 0.33 \\
Lodge with the husband & & \\
Yes & 253 & 84.33 \\
No & 47 & 15.67 \\
Number of children & & \\
[0 - 3] & 279 & 93 \\
[3 - 7] & 21 & \\
Profession & & \\
Yes & 27 & 9 \\
No & 273 & 91 \\
Salary employment & & 9 \\
Yes & 27 & 91 \\
No & & \\
\hline
\end{tabular}




\section{Continued}

Income-generating activity

Yes

No

Husband's income $(\mathrm{n}=286)$

Yes

No

Number of prenatal consultations

$0-3$

$4-7$

Location of follow-up

Gaspard Camara Health Center

Sicap Mbao Health Center

Knowledge of good nutrition practices

Food diversification

Yes

No

Hygiene practices used

Tap water consumption

Yes

No

Mineral water consumption

Yes

No

155

145

51.67

48.33

Water consumption from rainfall, wells, rivers

Yes

No

\section{Measurement of dietary diversity}

The dietary diversity measure was performed on a seven-day recall. The mean score over the seven days was 3.5 , with a median of 2.86 and a standard deviation of 1.75 .

Until day 3, the score was moderately diverse. The highest mean score was recorded on day one, corresponding to the 24-hour recall, 5.47, and the lowest was on day seven 0.81 (Table 2).

\section{Bivariate Analysis}

Factors associated with dietary diversity were age, location of follow-up, number of children, mineral water consumption, and husband's income.

Age was protective; women between 15 and 19 years were 1.14 times more likely to have a diverse diet during pregnancy than those over 19 years of age $(0.0007$ [ -1.8 to -0.48$])$.

Women followed at the Khadim Rassoul health center (CSKR) were 0.39 times more likely to have a diversified diet compared to those followed at the 
Gaspard CAMARA health center (0.004 [0.12 to 0.67]).

Having three or more children increased the chance of having a diversified diet by 0.56 times ( 0.04 [0.25 to 1.1$])$ compared to women who had fewer than three children.

Consumption of mineral water was a protective factor, increasing the chance of having a diverse diet by 0.27 times $(0.048$ [0.001 to 0.5$])$ compared to consumption of tap, well and rainwater.

Women with husband's income had 0.79 times the access to a diverse diet (0.005 [0.24 to 1.35$]$ ) compared to those for whom the husband had not (Table 3 ).

\section{Discussion}

Based on a qualitative recall of food consumption in the 24 hours preceding the

Table 2. Dietary diversity of women over a seven-day recall.

\begin{tabular}{cccc}
\hline Dietary Diversity Score & Mean & Median & Standard deviation \\
\hline Day 1 & 5.47 & 5 & 1.24 \\
Day 2 & 5.41 & 5 & 1.39 \\
Day 3 & 5.2 & 5 & 1.5 \\
Day 4 & 4.34 & 5 & 1.95 \\
Day 5 & 1.98 & 0 & 2.4 \\
Day 6 & 1.31 & 0 & 2.10 \\
Day 7 & 0.81 & 0 & 1.67 \\
Average score of the 7 days & 3.5 & 2.86 & 1.75 \\
\hline
\end{tabular}

Table 3. Factors associated with dietary diversity (by multiple linear regression).

\begin{tabular}{|c|c|c|c|}
\hline Factors associated & Adjusted $\beta$ coefficient & $95 \%$ confidence interval & P-value \\
\hline \multicolumn{4}{|l|}{ Age (years) } \\
\hline $16-19$ & Ref. & \multirow{2}{*}[-1.8;-0.48]{} & \multirow{2}{*}{0.0007} \\
\hline $20-45$ & -1.14 & & \\
\hline \multicolumn{4}{|l|}{ Location of follow-up } \\
\hline Gaspard CAMARA Health Center & Ref. & \multirow{2}{*}[0.12;0.67]{} & \multirow{2}{*}{0.004} \\
\hline Khadim Rassoul Health Center & 0.39 & & \\
\hline \multicolumn{4}{|l|}{ Number of children } \\
\hline$[0-3]$ & Ref. & \multirow{2}{*}[0.25;1.1]{} & \multirow{2}{*}{0.04} \\
\hline$[3-7]$ & 0.56 & & \\
\hline \multicolumn{4}{|l|}{ Mineral water consumption } \\
\hline No & Ref. & \multirow{2}{*}[0.001;0.5]{} & \multirow{2}{*}{0.048} \\
\hline Yes & 0.27 & & \\
\hline \multicolumn{4}{|l|}{ Husband's income } \\
\hline No & Ref. & \multirow{2}{*}[0.24;1.35]{} & \multirow{2}{*}{0.005} \\
\hline Yes & 0.79 & & \\
\hline
\end{tabular}


survey, we calculated the dietary diversity score of the women.

The average dietary diversity is 5.47 , which is approximately comparable to Mathilde SAVY results who obtained an average diversity of 5.1 for a sample of 691 mothers [6]. On the other hand, Elodie Becquey in her study "Validation of an indicator of dietary diversity by the adequacy of the diet in OUAGADOUGOU" found an average diversity equal to 4.2 [7], as did DIARRA in the Sikasso region who scored 4 [8].

Dietary diversity among pregnant women in the Dakar region was rated as average. This can be explained by the fact that the national dish "thieboudiene" alone contains three to four food groups. It is important to note that the majority of dishes consumed are derivatives of "thieboudiene" and contain more or less the same constituents (cabbage, turnip, carrot, eggplant, sorrel, peas, meat/fish). This means that by lunch, the woman had consumed three or four food groups, without considering the foods eaten at breakfast, dinner, and snacks.

Although women diversify their diets with national dishes, we observed a lack of variety in their diets. The same food groups were listed without dietary variation. We also noticed that the vegetables contained in the dishes were not really consumed but served as an ornament on their dish. Therefore the low consumption of fruits and vegetables (richer in nutrients) systematically implies a higher consumption of staple food (rice, sorghum, millet, root), and consequently a low intake of nutrients, as stated by SEBAI in a study on food security and diversity in Haiti in 2018 [9].

Our study revealed that the dietary diversity score was best in the 16 - 19 age group (1.14 [0.48 - 1.8]). This may seem paradoxical when at these ages, young girls are not experienced enough, some are primiparous. Being primiparous meant that girls paid more attention to their pregnancy and diet. It also makes sense that at these ages, they are newly married with fewer children, and the lack of burdens would justify this ability to feed themselves without difficulties.

Married women represented $95.33 \%$ of the total sample, this rate was close to that found by DIARRA which was $99 \%$ in the Sikasso region of Mali in 2017 [10].

The place where the pregnancy was monitored was associated with good dietary diversity (0.39 [0.12 - 0.67]). Indeed, women followed up in the Gaspard Camara health center in urban areas had a lower diversity than those followed up in the Khadim Rassoul health center in peri-urban areas. This could be explained by the fact that the health care personnel did much more nutritional education during prenatal consultations. But also, women in peri-urban areas have a more permanent relationship with household chores, cooking and food compared to those in urban areas who are known to be more involved in administrative jobs and do not find enough time to eat well. In contrast, the results of a study in Mali on household dietary diversity scores by residence and season showed a higher dietary diversity score in urban and low rural areas [11].

Women who had made more than three visits had a slightly higher dietary di- 
versity score of 5.67 [ 2.88 - 8.45] than women who had made less than three visits, 5.41 [3.11 - 7.7]. This could influence fetal development and birth weight. Moreover, a study on the evaluation of food consumption profiles and nutritional status of the populations of the Centre-West region of Burkina Faso by Ousmane O. showed that the nutritional status of the mother before pregnancy, the weight of the mother during the last consultation, the sex and the head circumference of the newborn were associated with low birth weight [12].

Women with three or more children had a more diverse diet than those with fewer than three children $(0.56$ [0.12 - 0.67]). Indeed, women with more than 3 children had better income than those without $(\mathrm{OR}=3.13[1.1-8.78])$. This could explain the better dietary diversification among these women with more than 3 children knowing that the economic level of the household can influence the Dietary Diversity Score in women.

Women's income and education level had no influence on their dietary diversity in accordance with the results found by Ines Sebai who instead revealed that women's dietary diversity appeared to be influenced by the number of sources of income in the last 30 days as well as women's education level [13]. Also, Ousmane O. (Burkina Faso 2020) had established a link between the level of education and dietary diversity of women [12].

However, the income of the head of the household had an influence on the quality of the diet in women by improving the dietary diversity score $(0.79[0.24$ - 1.35]). A study on the relationship between production diversity, farm income and dietary diversity in rural Burkina Faso [14] revealed that women receiving a cash transfer from the farm or household head had better dietary diversity in all seasons. In this same pace, another study done on the assessment of factors associated with low consumption and dietary diversity scores in households in the Sikasso and Mopti region in July 2017, also associates household income with better dietary diversity [15]. On the other hand, a study done in Togo on the link between socioeconomic profiles and food security reveals that belonging to a socioeconomic class weakly determines the quality of dietary diversity, indeed, households with low income (poor) had medium and high dietary diversity [16].

The activities oriented in the production of food products had no effect on the dietary diversity score. In accordance with the results found by Lourme Ruiz and his collaborators [14], who concluded that "the control of resources by women seems to be a better guarantor of the quality of their food than the level of agricultural production, of the farm". This was proven by a study carried out in Sikasso, Mali by Dury on the persistence of malnutrition among children despite high agricultural production [17]. In fact, we can say that agricultural production only partially solves the problem of food insecurity insofar as there is a perennial food supply, but it does not solve the problem of food diversity. Contrary to Ines Sebai who linked women's dietary diversity to livestock production [13].

In our study, the only knowledge and practice that was statistically related to dietary diversity of pregnant women was mineral water consumption $(0.27$ 
[0.001 - 0.5]). The result was that women who consumed mineral water had a better mean dietary diversity score of 5.57 compared with those who did not. This could be explained by the fact that they would have a good socioeconomic level than those who consumed well, rain and river water, and tap water.

\section{Conclusion}

The diet of the pregnant woman from the first day of conception has an impact on the quality of the fetus and the future human being. The pregnant woman should be at the heart of several nutritional studies in order to improve her health, that of the fetus, but also in order to provide for healthy humans. To date, the diet of pregnant women has not been the subject of much research in Senegal. The present study has allowed us to obtain data on the dietary diversity of pregnant women in the Dakar region, but more importantly, to understand the factors associated with dietary diversity among pregnant women, which are: age, place of follow-up, number of children, consumption of mineral water, and husband's income.

\section{Acknowledgements}

Institute of Health and Development;

Gaspard CAMARA Health Center;

Khadim Khassoul Health Center.

\section{Conflicts of Interest}

The authors declare no conflicts of interest regarding the publication of this paper.

\section{References}

[1] OMS. Malnutrition: The Challenges. http://www.who.int/nutrition/challenges/fr

[2] (2013) National Food Security and Nutrition Survey (NFSS).

[3] (2009) World Food Program. Emergency Food Security Assessment Manual. 30.

[4] National Agency of Statistics and Demography (2013) Economic and Social Situation Regional.

[5] Tine, J.A.D., Niang, K., Faye, A. and Dia, A.T. (2018) Assessment of Women's Dietary Diversity in Southern Senegal. Food and Nutrition Sciences, 9, 1192-1205. https://doi.org/10.4236/fns.2018.910086

[6] Barker, D.J. and Osmond, C. (1986) Infant Mortality, Childhood Nutrition, and Ischaemic Heart Disease in England and Wales. The Lancet, 1, 1077-1081. https://doi.org/10.1016/S0140-6736(86)91340-1

[7] Action against Hunger. Welding Survey on the Food Diversity of Mothers and Children Aged 6-59 Months in Three Communes of the PADABA Project.

[8] Diarra, F. (2017) Assessment of Factors Associated with Low Food Consumption and Diversity Scores in Households in the Sikasso and Mopti Regions in July. 58.

[9] Sebai, I. (2018) Household Food Security and Diversity in Haiti. 81. 
[10] Diarra, M.F. (2018) Assessment of Factors Associated with Low Food Consumption and Diversity Scores in Households in the Sikasso and Mopti Regions in July 2017. 56.

[11] Auteurs (2014) Dietary Diversity Scores of Households in Mali, by Residence and Season (2014-15).

[12] Ouédraogo, O. (2020) Evaluation of the Food Consumption Profiles and Nutritional Status of the Populations of the Centre-West Region of Burkina Faso.

[13] Sebai, I. (2018) Household Food Security and Diversity in Haiti. 83.

[14] Savy, M. (2006) Dietary Diversity Indices: Measurement and Use in Women of Childbearing Age in Burkina Faso. Doctoral Thesis.

[15] Diarra, F. (2018) Assessment of Factors Associated with Low Food Consumption and Diversity Scores in Households in the Sikasso and Mopti Regions in July 2017. 59.

[16] Lare, F. and Boubacar, S. (2021) Link between Socio-Economic Profiles and Food Security of Rural Households in the Prefecture of Tandjouare in Northern Togo. 145.

[17] Cardon, P. (2010) A Sociological Look at the Dietary Practices of Older Adults Living at Home. 31-42. 